\title{
Epidemiology and Characteristics of Cervical Spine Injury in Patients Presenting to a Regional Emergency Department
}

Etimbuk Umana ${ }^{1}$, Khalid Khan ${ }^{1}$, MN Baig ${ }^{2}$, James Binchy ${ }^{1}$

1. Department of Emergency Medicine, University Hospital Galway 2. Orthopaedics, University Hospital Galway, Galway, IRL

$\square$ Corresponding author: Etimbuk Umana, mutip001@hotmail.com

Disclosures can be found in Additional Information at the end of the article

\section{Abstract}

\section{Purpose}

This study aims to establish the demographics and characteristics of patients with cervical spine injury (CSI) in an Irish cohort presenting to a regional emergency department.

\section{Methods}

We performed a retrospective analysis of the medical records of patients who underwent cervical spine computed tomography (CT) scans following trauma from January 2013 to July 2016. We looked at the mechanism of injury, mode of arrival to the emergency department, triage category, correlation between examination, and site of CSI and neurological status.

\section{Results}

Over the study period, 808 patients underwent CT scans of the cervical spine for potential CSI. The incidence of CSI in our cohort was $9.4 \%(n=76)$. Approximately $70 \%(n=53)$ were men. Falls (53\%) and motor vehicle accidents (29\%) were noted to be the more common mechanisms of injury in this cohort. The $\mathrm{C} 2$ region was the most common location for CSI. Only $7 \%(\mathrm{n}=5)$ of patients had documented neurology.

\section{Conclusion}

This study demonstrates the epidemiology and characteristics of CSI presenting in an Irish cohort. The incidence of CSI was found to be $9.4 \%$ with a male preponderance and falls being the most common cause of trauma.

Received 01/22/2018

Review began 01/29/2018 Review ended 02/06/2018 Published 02/10/2018

\section{(c) Copyright 2018}

Umana et al. This is an open access article distributed under the terms of the Creative Commons Attribution License CC-BY 3.0., which permits unrestricted use, distribution, and reproduction in any medium, provided the original author and source are credited.
Categories: Emergency Medicine, Orthopedics, Epidemiology/Public Health Keywords: cervical spine injury, incidence, computer tomography

\section{Introduction}

Cervical spine injury (CSI) has been widely reported in patients with blunt trauma and represents an important subgroup presenting to the Emergency Department (ED). There is a variation in incidence and epidemiological data of patients presenting with CSI in different populations [1-7]. The incidence of CSI ranges from $2 \%$ to $12 \%$, with a higher incidence in those who are obtunded or intoxicated and patients who are difficult to evaluate clinically [1-4]. Most 
studies have reported a bimodal age distribution with the first peak between 15 years to 45 years and a second peak for those aged 65 years to 80 years $[1,2,8,9]$. With respect to gender, CSI is more common in men $[1,2,5-7]$. CSI with cord injury can be devastating and can lead to permanent, irreversible disability. Therefore, patients with suspected CSI undergo cervical spine immobilization and systematic evaluation to identify patients with significant injuries. This study aims to establish the demographics and characteristics of patients with CSI presenting to an Irish regional ED. These characteristics include mechanism of injury, mode of arrival to the ED, triage category, the correlation between examination and site of CSI, neurological status, and management outcome.

\section{Materials And Methods}

This was a retrospective study carried out in a regional tertiary university hospital in the West of Ireland with an annual attendance of over 65,000 presentations to the ED. This study period was from January 2013 to July 2016, inclusive. The patients who underwent cervical spine computed tomography (CT) scan following blunt trauma to the cervical spine were identified through the hospital radiology registry (PACS System). Variables retrieved included age, gender, triage category, Glasgow Coma Scale (GCS), mechanism and site of injury, mode of arrival, and clinical correlation with fracture site on CT. Neurological status and management outcomes were also documented.

\section{Results}

Over the study period, 808 patients underwent CT cervical spine for potential CSI. The incidence of CSI in our cohort was $9.4 \%(n=76)$. Approximately $70 \%(n=53)$ were men, and the mean age of patients presenting with CSI was 53.8 (standard deviation (SD), 23.2).

Approximately $61 \%$ of patients were under 60 years of age but only $7.9 \%$ were under 20 years of age. Table 1 gives an overview of patient characteristics presenting with CSI. Falls (53\%) and motor vehicle accidents (MVA; 29\%) were the more common mechanisms of injury in our patient cohort. Cyclist road traffic accident (RTA; 8\%), pedestrian RTA (5\%), sports, (1\%) and others (4\%) made up the remainder. A decreasing trend regarding the incidence of falls was noted from 2013 to 2016 (Figure 1). 


\section{Cureus}

\begin{tabular}{|c|c|c|}
\hline Characteristics & & $\%(n)$ \\
\hline \multirow[t]{2}{*}{ Gender } & Male & $70 \%(53)$ \\
\hline & Female & $30 \%(23)$ \\
\hline Age & Mean/SD (Range) & 53.8/23.2 (6-99) \\
\hline \multirow[t]{6}{*}{ Mechanism of injury } & Falls & $53 \%(40)$ \\
\hline & MVA & $29 \%(22)$ \\
\hline & Cyclist RTA & $8 \%(6)$ \\
\hline & Pedestrian RTA & $5 \%(4)$ \\
\hline & Sports & $1 \%(1)$ \\
\hline & Others & $4 \%(3)$ \\
\hline \multirow[t]{3}{*}{ Mode of arrival } & Ambulance & $76.3 \%(58)$ \\
\hline & Helicopter & $2.6 \%(2)$ \\
\hline & Private transport & $21.1 \%(16)$ \\
\hline Alcohol related & & $9 \%(7)$ \\
\hline GCS & Mean/SD (Range) & 13.9/2.7 (3-15) \\
\hline \multirow[t]{4}{*}{ MTS } & Category 1 & $21 \%(16)$ \\
\hline & Category 2 & $43 \%(33)$ \\
\hline & Category 3 & $28 \%(21)$ \\
\hline & Category 4 & $8 \%(6)$ \\
\hline \multirow[t]{3}{*}{ Neurology } & Abnormal & $7 \%(5)$ \\
\hline & Intact & $85 \%(65)$ \\
\hline & $\mathrm{N} / \mathrm{A}$ & $8 \%(6)$ \\
\hline \multirow[t]{2}{*}{ Management } & Conservative & $76 \%(58)$ \\
\hline & Surgery & $24 \%$ (18) \\
\hline
\end{tabular}

\section{TABLE 1: Patient characteristics $(\mathbf{n}=\mathbf{7 6})$.}

SD: Standard deviation; MVA: Motor vehicle accident; RTA: Road traffic accident; MTS: Manchester Triage System; N/A: Not assessed. 


\section{Cureus}

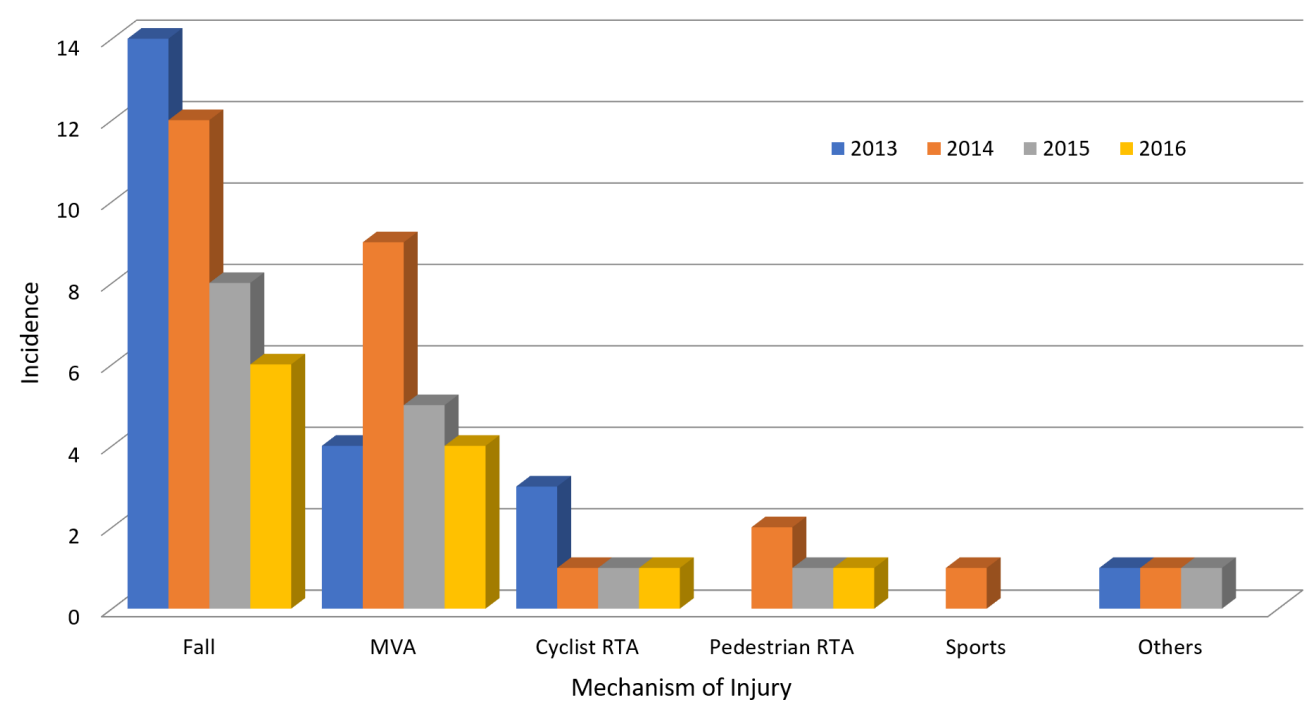

FIGURE 1: Trends of mechanism of injury in cervical spine injuries.

MVA: Motor vehicle accident; RTA: Road traffic accident.

Most patients arrived at the ED by ambulance (76\%). An assessment of the seasonal trend of injury presentations revealed that January, May, and August are the more common months for injury presentation (Figure 2). Only $9 \%(n=7)$ of patients with CSI were noted to have an alcohol-related presentation. The mean GCS for our cohort was 13.9 (SD, 2.7), with some patients presenting with a GCS as low as 3. Patients were triaged according to the Manchester Triage System and were given one of four triage categories. Most patients were triaged as Category 1 or 2 (64.5\%), while 35.5\% were triaged Category 3 or 4 . On examination, 67 patients had a documented area of tenderness. Of the 67 patients, a clinical exam correlated with the site of the fracture on the cervical spine CT scan in $49 \%(n=33)$ of patients. Figure 3 illustrates the correlation between clinical exam and fracture site.

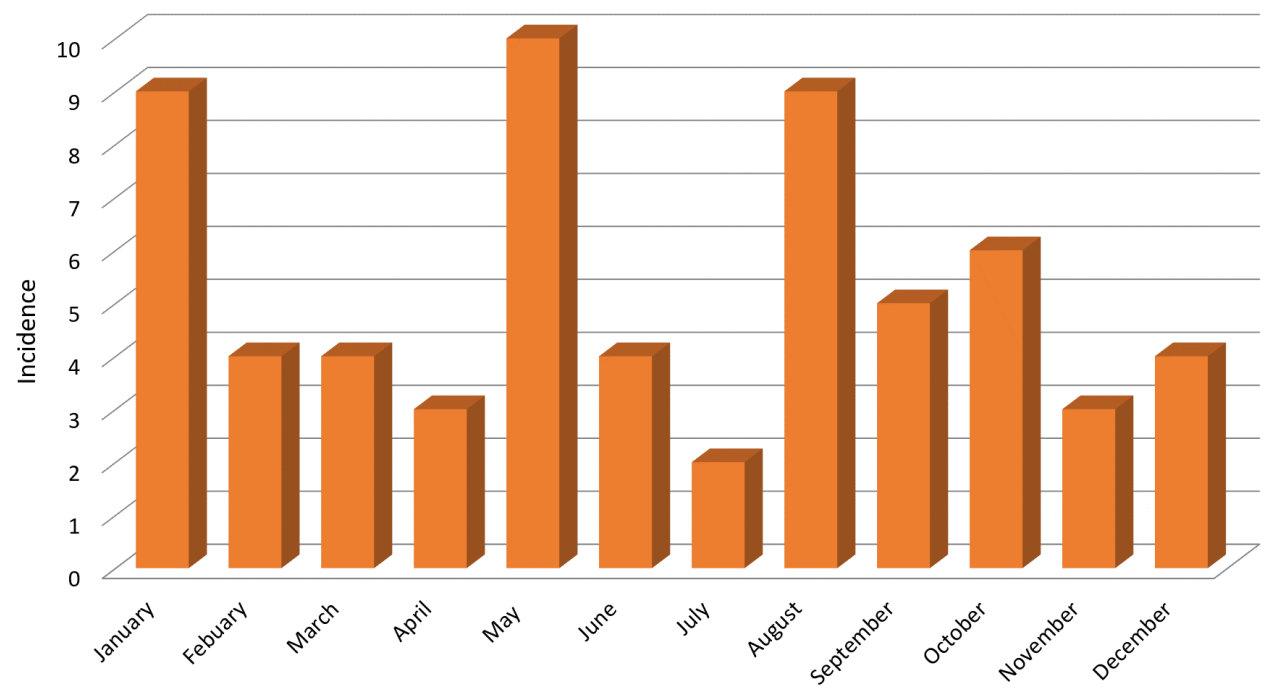

FIGURE 2: Seasonal trend in injury presentation. 


\section{Cureus}

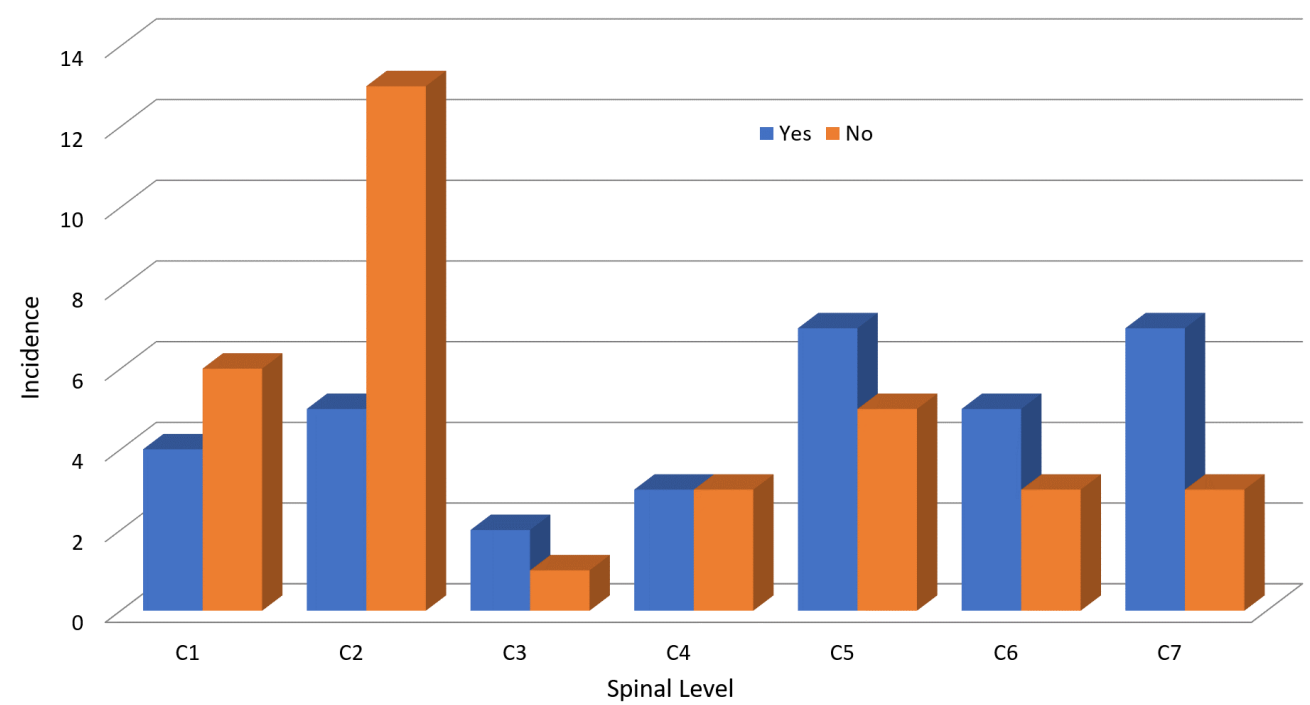

FIGURE 3: Clinical correlation with fracture site.

The C2 region was the most common level for the location of CSI (Figure 4), closely followed by $\mathrm{C} 5$ and $\mathrm{C} 1$ regions. The highest incidence of $\mathrm{C} 2$ fractures was observed in those above 80 years of age with falls representing the most common mechanism of injury. Sixteen patients had more than one level of CSI, with $\mathrm{C} 1-\mathrm{C} 2, \mathrm{C} 5-\mathrm{C} 6$, and C5-C6-C7 representing the more common combination of injury. Only $7 \%(n=5)$ of patients had documented abnormal neurology, the rest either had intact neurology or no documentation of neurological status. Seventy-six percent $(n=58)$ of the patients with CSI were managed conservatively while the rest needed surgical intervention.

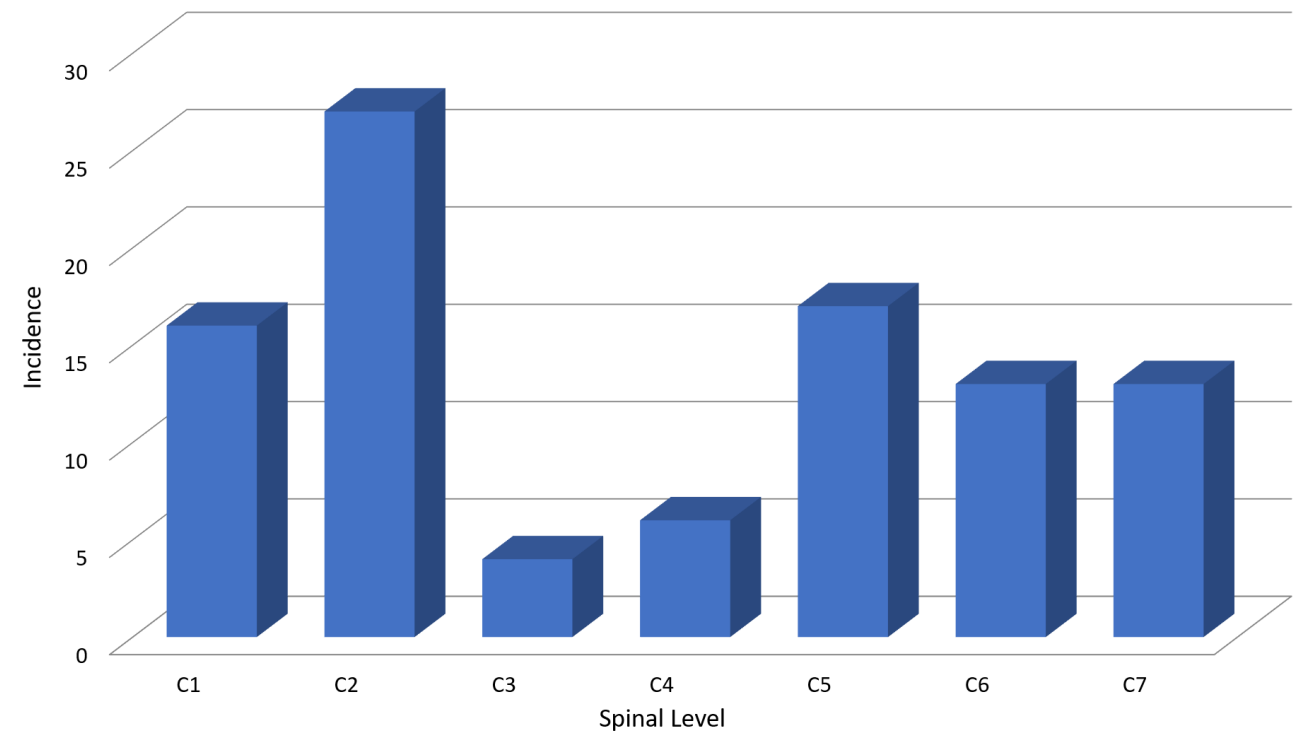

FIGURE 4: Level of injury. 


\section{Discussion}

Our study will be the first to focus on patients presenting with CSI from the general population in the West of Ireland. The incidence of CSI in our cohort was 9.4\%, which is within the range of $2 \%$ to $12 \%$ found in the published literature [1-5]. Unlike past studies that described a bimodal age distribution in patients presenting with CSI $[1,2,8-10]$, we found that $61 \%$ of patients were younger than 60 years of age, with a peak incidence between 20 and 30 years and 50 and 60 years of age. The remaining $39 \%$ included those older than 60 years with a peak incidence occurring between the ages of 80 and 90 years of age. Other studies have reported an increased incidence of CSI with increasing age, a trend we did not observe in our study $[2,6]$. In terms of gender distribution, our study found a male predominance of $70 \%$, which aligns with previous studies on CSI $[1,2,5-7]$.

Very few authors report falls as the most common mechanism of injury for CSI [6], with the majority reporting MVAs as the most common followed closely by falls $[1,2,4,7]$. We also noted the mean age for falls was 61.1 years which was higher than other causes of injury in our study. The decreasing incidence of falls in the data set could be associated with measures to increase safety at work and fall prevention programs instituted within the community. Urdaneta, et al. analyzed patients with CSI based on the mode of arrival and found 93\% of patients arrived via Emergency Medical Services while 7\% arrived via private transport. Twenty-one percent of our study population arrived by private transport and were more likely to be triaged as Category 3 and 4, with two patients requiring surgical intervention. As Urdaneta, et al. stipulated, patients arriving by private transport represent a low-risk group with potential for significant injury requiring surgery, and ED providers should maintain high levels of vigilance for CSI in this cohort. C2 was the most common level involved for CSI, which aligns with prior studies $[5,6]$. This was closely followed by C5 and C1 cervical vertebrae. Though injury at C2 was the most common level of CSI reported, clinical exams did not correlate with the fracture site on cervical spine CT scans. In comparison, tenderness over C5 to C7 on examination was more likely to correlate with a fracture site on a cervical spine CT.

Understanding the demographics of our patient population, their mechanism of injury, and expected findings can better help us prepare to manage this cohort when they present to the ED.

\section{Conclusions}

This study demonstrates the epidemiology and characteristic of CSI presenting in an Irish cohort. The incidence of CSI was found to be $9.4 \%$ with a male preponderance and falls being the most common cause of trauma. This study is important as it would help with resource and personnel allocation to improve our services and optimize the management of patients presenting with CSI.

\section{Additional Information}

\section{Disclosures}

Human subjects: All authors have confirmed that this study did not involve human participants or tissue. Animal subjects: All authors have confirmed that this study did not involve animal subjects or tissue. Conflicts of interest: In compliance with the ICMJE uniform disclosure form, all authors declare the following: Payment/services info: All authors have declared that no financial support was received from any organization for the submitted work. Financial relationships: All authors have declared that they have no financial relationships at 
present or within the previous three years with any organizations that might have an interest in the submitted work. Other relationships: All authors have declared that there are no other relationships or activities that could appear to have influenced the submitted work.

\section{References}

1. Clayton JL, Harris MB, Weintraub SL, et al.: Risk factors for cervical spine injury . Injury. 2012, 43:431-435. 10.1016/j.injury.2011.06.022

2. Lowery DW, Wald MM, Browne BJ, et al.: Epidemiology of cervical spine injury victims . Ann Emerg Med. 2001, 38:12-16. 10.1067/mem.2001.116149

3. MacDonald RL, Schwartz ML, Mirich D, et al.: Diagnosis of cervical spine injury in motor vehicle crash victims: how many X-rays are enough?. J Trauma. 1990, 30:392-397. 10.1016/S0196-0644(05)81232-6

4. Martin MJ, Bush LD, Inaba K, et al.: Cervical spine evaluation and clearance in the intoxicated patient: a prospective Western Trauma Association Multi-Institutional Trial and Survey. J Trauma Acute Care Surg. 2017, 83:1032-1040. 10.1097/TA.0000000000001650

5. Malik SA, Murphy M, Connolly P, et al.: Evaluation of morbidity, mortality and outcome following cervical spine injuries in elderly patients. Eur Spine J. 2008, 17:585-591. 10.1007/s00586-008-0603-3

6. Fredø HL, Rizvi SA, Lied B, et al.: The epidemiology of traumatic cervical spine fractures: a prospective population study from Norway. Scand J Trauma Resusc Emerg Med. 2012, 20:85. 10.1186/1757-7241-20-85

7. Yadollahi M, Paydar S, Ghaem H, et al.: Epidemiology of cervical spine fractures . Trauma Mon. 2016, 21:33608. 10.5812/traumamon.33608

8. McCabe JB, Angelos MG: Injury to the head and face in patients with cervical spine injury . Am J Emerg Med. 1984, 2:333-335. 10.1016/0735-6757(84)90130-X

9. Ryan MD, Henderson JJ: The epidemiology of fractures and fracture-dislocations of the cervical spine. Injury. 1992, 23:38-40. 10.1016/0020-1383(92)90123-A

10. Baig M: A review of epidemiological distribution of different types of fractures in paediatric age. Cureus. 2017, 9:1624. 10.7759/cureus.1624 